\title{
The impact of rural health insurance and the family physician program on hospitalizations, a before- after study at the county level conducted in Tehran province, Iran
}

\author{
Sedigheh Salavati ${ }^{1}$, Arash Rashidian*1, Sara Emamgholipour ${ }^{1}$, Vida Varahrami ${ }^{2}$ \\ Received: 30 Jan 2017 \\ Published: 18 Apr 2018
}

\begin{abstract}
Background: The health insurance and family physician reform in Iran were implemented in 2005. This study was conducted to assess the effect of these reforms on avoidable hospitalizations among the rural population of Eslam-shahr County, Iran.

Methods: We conducted a before-after study in Eslam-shahr County's single existing hospital. This county is a part of the Tehran Province of Iran. The demographic characteristics and diagnostic codes of the rural population that were hospitalized during the 2 years leading to, and after the reforms were extracted from the hospital's electronic information system. A list of 61 three-character and 131 four-character AHs codes were developed based on the literature review. We estimated a logistic regression model which included gender and age as independent variables to assess changes in the probability of avoidable hospitalizations following reform implementation. Analyses were carried out using STATA version 13

Results: We recorded 817 rural hospitalizations before and 967 hospitalizations after reform implementation, suggesting that hospitalization growth after the reforms was almost $18.4 \%$. The logistic regression results show that the probability of avoidable hospitalizations after the interventions had decreased compared to before the interventions were put into place (OR: 0.46 ; 95\% CI: 0.24-0.88). Also, the probability of AHs among the $60<$ year-old age group was considerably higher compared to other age groups. No statistical relationship was found between avoidable hospitalizations and gender.

Conclusion: The reforms may have had a mixed effect on hospitalization. They may result in increased hospitalizations due to responding to the unmet needs of the population, and simultaneously they may lead to a decrease in avoidable hospitalizations and eliminate the costs imposed by them upon the health system.
\end{abstract}

Keywords: Family physician, Health insurance, Hospitalization, Rural health

Copyright@ Iran University of Medical Sciences

Cite this article as: Salavati S, Rashidian A, Emamgholipour S, Varahrami V. The impact of rural health insurance and the family physician program on hospitalizations, a before-after study at the county level conducted in Tehran province, Iran. Med J Islam Repub Iran. $2018(18$ Apr);32:32. https://doi.org/10.14196/mjiri.32.32

\section{Introduction}

Universal health coverage (UHC) aims to ensure that all people, whether rich or poor, have access to effective health services that meet most of their health needs, without being exposed to the risk of financial hardship (1). Actions on Universal Health Coverage can have mixed effects on hospitalization rates. The development of health

insurance services will remove financial barriers that prevent access to secondary health care services, and will therefore increase hospitalization rates (2-5). Expansion of Primary Health Care (PHC) - an approach that has been approved as a global strategy by the WHO to reduce costs and improve health care quality (2-4) results in an increase

Corresponding author: Dr Arash Rashidian, arashidian@tums.ac.ir

1. Department of Health Management and Economics, School of Public Health, Tehran University of Medical Science, Tehran, Iran.

2. Department of Economics, School of Economics and Political Sciences, Shahid Beheshti University, Tehran, Iran.

$\uparrow$ What is "already known" in this topic:

The family physician program and rural health insurance were implemented in all rural areas in Iran in 2005, and no previous study has assessed effects of these reforms on hospitalizations especially avoidable hospitalizations.

\section{$\rightarrow$ What this article adds:}

This study provides some evidence of the efficiency and access effects of the reform. The reform resulted in increasing unavoidable hospitalizations (improving access to hospital care) and decreasing avoidable hospitalizations (improving efficiency and effectiveness of primary care). 
in referral-sensitive hospitalizations by identifying unmet needs (5-7) and also decreases avoidable hospitalizations by providing timely preventive care $(8,9)$. Avoidable or preventable hospitalizations are hospitalizations that timely and effective primary care could prevent the need for hospitalization $(9,10)$. Avoidable hospitalization rates used as indicators for access or quality of primary health care services $(11,12)$.

Iran has enjoyed an extensive network of publicly funded primary health-care services in rural areas since the mid-1980s. A "health house" is a part of the district PHC network. It is staffed by one or two Behvarz's who serve an average population of around 1500 (13). PHC networks have achieved great results in promoting the health of the general population, but problems such as financial barriers that prevent the rural population from receiving secondary care, poor referral systems and epidemiological changes such as increase in the rates of chronic diseases led to the development of reforms in 2005 (14). Based on these reforms, all rural areas and towns with a population of less than 20000 people were covered by a rural health insurance program funded by the Iran Health Insurance Organization (IHIO). The family physician program was simultaneously carried out in these areas, and around 6000 physicians and 4000 midwives were added to the PHC network (15).

In order to assess the effect of these reforms on hospitalizations, Rashidian et al. conducted a study in an underserved province in Iran. The results showed that hospitalization rates increase up until one year after the interventions. However, this study did not present any findings about the effect of reforms on avoidable hospitalizations (AHs) (6). In this study, we explored the effects of reforms on total and avoidable hospitalizations in Eslamshahr, a county in the capital of Iran.

This county has 131 villages and its rural population is approximately 49237, based on the 2006 census that was conducted one year after the implementation of reforms. Eslam-shahr has only one hospital, which is financed by the Social Security Insurance Organization (SSIO). The population under coverage of the SSIO receives hospital services free of charge. This hospital is the main place where the rural residents of Eslam-shahr County receive secondary health care services, due to its proximity to rural areas. The rural population under coverage of the SSIO does not face any financial barriers in using these hospital services. After actions were taken for the development of UHC in 2005, all rural residents had access to a rural family physician, where they would receive timely primary care, and if necessary, could be referred to the county hospital. Also, all of the rural populations were covered by the rural health insurance system; therefore those rural residents who had previously lacked SSIO coverage no longer faced financial barriers for using hospital services. It should be noted that as of 2005, parts of the rural population were covered by 2 health insurance systems, both the rural health insurance and the health social security insurance system.

Although it was not possible to identify those with dual insurance coverage in this study, we did however manage to distinguish the effect of the family physician on both avoidable and referral-sensitive hospitalization rates.

\section{Methods}

We conducted a before-after study, which is a type of quasi-experimental study. The setting of the study was Eslam-shahr. We selected Eslam-shahr county for this study due to the fact that it was the only hospital with a functioning electronic hospital information system during the time period of our study, whereas other hospitals lacked an electronic record system, and their paper medical records had been eliminated due to the expiration of their legal archival records.

We extracted the demographic characteristics of any members of the rural population that were hospitalized during the 4 years from April 2003 to April 2008 (2 years before and 2 years after the intervention) from the hospital's electronic information system. These characteristics included their age and gender and diagnostic codes. The diagnostic codes were recorded based on ICD10. Some countries have determined a list of avoidable diagnostic codes, however in Iran there is no research-based predetermined AHs diagnostic code list, and therefore we used data from studies conducted in other countries. We identified a list of 61 three-character and 131 fourcharacter AHs diagnostic codes based on the literature review. These diagnostic codes are used as indicators for assessing the accessibility or effectiveness of primary health care services in Germany, England and Canada (1618).

Results are presented using descriptive statistics. Also, the logistic regression model has been used to assess whether the probability of AHs changes following implementation of the reforms. We included gender and age as independent variables in the model and we estimated Odds ratio with a $95 \%$ confidence intervals. We conducted several diagnostic tests after development of the model. Linktest results showed no specification errors in the Logit model. Hosmer and Lemeshow statistics showed an appropriate goodness of fit, and no co-linearity among the independent variables. All analyses were carried out using STATA version 13 and SPSS version 18 software.

\section{Results}

Results showed that there were 817 rural hospitalizations before the reforms and 967 after the reforms, and total hospitalization growth after the reforms was almost $18.4 \%$. Avoidable/total hospitalizations show a $1.3 \%$ decrease following the reforms (Table 1).

Total hospitalizations before the reforms were 242 among men and 560 among women. Following the reforms, the number of total hospitalizations among men (264 cases) was lower than among women (682 cases). Hospitalizations in both genders were often related to the referral-sensitive hospitalizations. Referral sensitive hospitalizations before and after the reforms were 230 and 252 hospitalizations, respectively, among men, and 546 and 674 cases, respectively, among women.

Before the reforms, the percentage of avoidable hospitalizations was $5.8 \%$ among men and $2.5 \%$ among wom- 
Table 1. Frequency of rural hospitalizations 2 years before and after the reforms implementations (April 2003- April 2008)

\begin{tabular}{|c|c|c|c|}
\hline \multirow[b]{3}{*}{ Before reforms } & \multicolumn{3}{|c|}{ Type of hospitalization } \\
\hline & Avoidable hospitalizations (\%) & Unavoidable hospitalizations (\%) & Total hospitalizations \\
\hline & $29(3.5)$ & $788(96.5)$ & 817 \\
\hline After reforms & $21(2.2)$ & $946(97.8)$ & 967 \\
\hline
\end{tabular}

Table 2. Frequency of rural hospitalizations, before and after the reforms implementations, based on age (April 2003- April 2008)

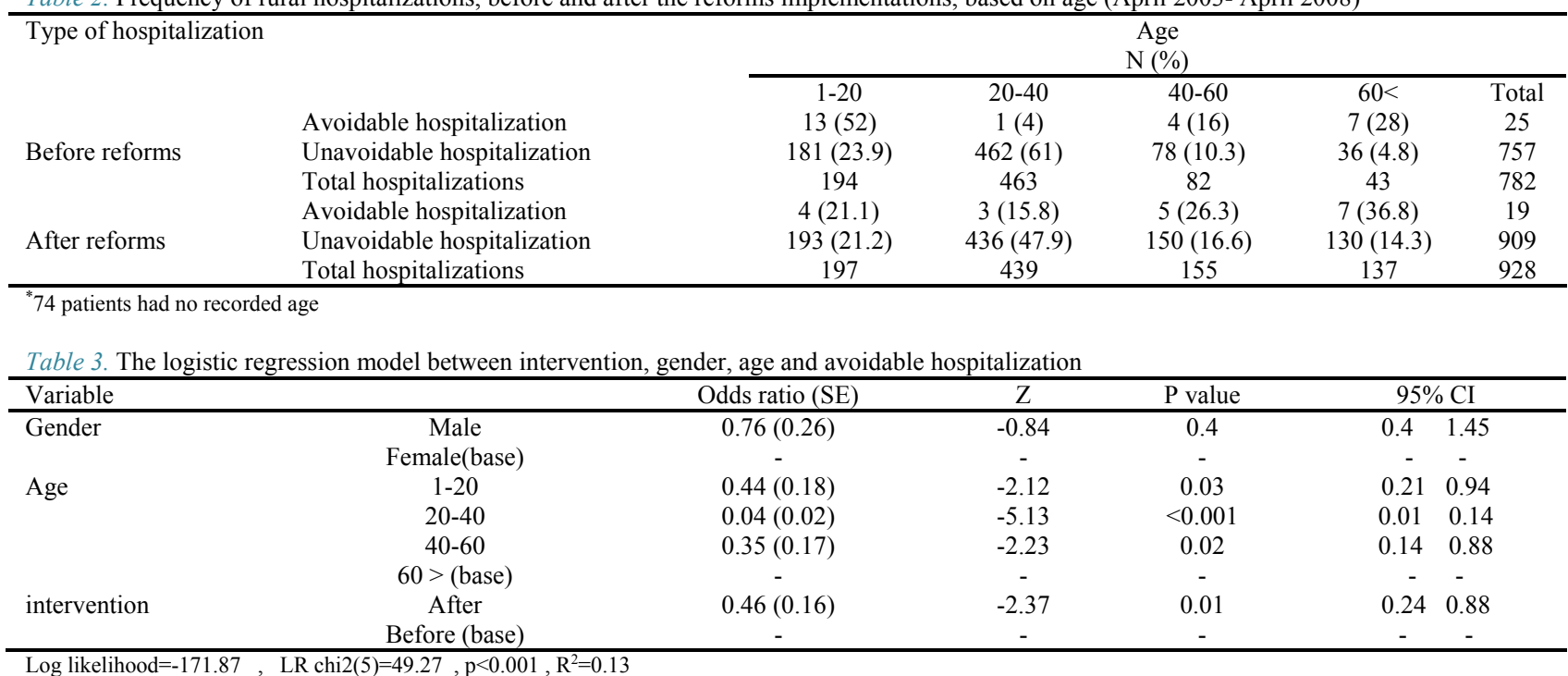

p $<0.001, \mathrm{R}^{2}=0.13$

Husmer Lemeshow statistics: Chi $2(6)=3.90, \mathrm{P}=0.69$

en. Following the reform, this percentage dropped to $4.5 \%$ among men and $1.2 \%$ among women. Based on these results, the percentage of avoidable hospitalizations among men was higher than women, both before and after the reforms, and this percentage decreased after reforms among both genders.

Results showed that total hospitalizations were higher among the 20-40 year-old population, both before and after the interventions. The AHs in this age group were lowest throughout the study. The highest AHs occurred among those aged 1-20, before the reforms were carried out. The highest AHs were seen among the $60<$ year old population, following the interventions (Table 2).

The logistic regression results showed that after demographic characteristics are taken into account, the probability of AHs after the interventions was lower compared to before the interventions (OR:0.46; 95\% CI; 0.24-0.88). Also, the probability of AHs in the $60<$ year-old age group is considerably higher compared to other age groups $(\mathrm{p}<0.05)$. No statistical relationship was found between AHs and gender (Table 3).

\section{Discussion}

Results showed an increase in total rural hospitalizations compared to before the interventions. Although the percentage of avoidable/total hospitalizations was low both before and after the interventions, however, we noticed a significant decrease in AHs following the reforms.

Since some rural residents had coverage by the Social Security Health Insurance before reform implementation and could therefore access hospital services without any financial barriers, this might explain the low rates of AHs witnessed before and after the interventions. However, we also saw an increase in the referral-sensitive hospitalizations (unavoidable hospitalizations) following reforms implementation, which may result from the reforms' response to the unmet needs of the rural population.

A previous study conducted in an underserved province in Iran showed similar findings, with a significant increase in hospitalization rates one year after implementation of reforms (6). In confirmation of our results, a systematic study showed that a strong primary health system (with a greater supply of physicians and continuity of care), resulted in a decrease in Ahs (12). In the US, increased insurance coverage and programs for increasing access to primary care among children resulted in elimination of Ahs (19). In London, providing primary special diabetic services resulted in a decrease in AHs, however, this was not seen in asthma-related hospitalizations (20). Expansion of family health programs prevented AHs among children under 5 in Brazil (21).

Study of the aspects and characteristics of PHC showed results that were at times contradictory to ours. The supply and distribution of physicians had little effect on avoidable and total hospitalizations among Medicaid beneficiaries (22). In a study carried out in the US, the supply of physicians had no relation with AHs in rural areas (23). However, some studies exploring the aspects of PHC in detail showed similar results to ours. For example, 2 studies in Canada showed decreased referral to emergency departments (24) and avoidable hospitalizations (25) among those of the elderly who had continuous contact with PHC physicians.

It seems that the UHC interventions in the rural areas of Eslam-shahr affected both health care access (by increasing referral-sensitive hospitalizations) and efficiency, by decreasing AHs. Therefore,we can state that, UHC inter- 
ventions may increase long-term health care costs by enforcing referral-sensitive hospital expenditures, and on the other hand, they may also decrease these costs by preventing AHs.

In the US, it has been estimated that the development of UHC resulted in increased ambulatory care sensitive hospitalization and, as a result, in increased health expenditure (26). Also, expansion of the basic insurance system in China resulted in hospitalization growth (27).

In our study, the effect of socioeconomic factors on hospitalization was not explored, and only the demographic characteristics of the rural population were considered. Results showed that there is no relation between gender and AHs. Contradictory to our results, in Brazil the effectiveness of the primary care community-based program resulted in decreased AHs for diabetes and pulmonary diseases, with this effect being greater among women (28). In our study, AHs were statistically related to age, with rates being higher among the $60<$ age group. It seems that this could be due to the higher rates of chronic diseases in this age group, since the diagnosis of these diseases falls under the category of AHs.

Our study strength is in the use of the before-after design in measuring the program effects. Also, we determined the reform effects on both avoidable and referralsensitive hospitalizations. This gives policymakers a comprehensive picture of the effect of the reforms on both access and efficiency. However, our study had some limitations. One was the lack of a control group to ensure that other interventions had not affected the intervention group or rural population hospitalization. Another was conducting the study at the county level. The characteristics of the rural population, especially the access of a number of people to another insurance service means that our results cannot be generalized to other counties in Iran. Also, we were unable to measure the effect of factors such as the socio-economic characteristics of the rural population those of which were using hospital services - or their initial health status, since we had no access to these data. Despite these limitations, our study results provide a good basis for future studies aiming to assess reform effects, in relation with the contextual characteristics of rural areas in each county.

\section{Conclusion}

The family physician program and expansion of health insurance may have a mixed effect on hospitalization. On the one hand, it could result in increased hospitalizations due to the identification of and response to the unmet needs of the population, and on the other hand it could decrease AHs and eliminate the costs imposed by them upon the health system.

\section{Acknowledgments}

We would like to thank the head of research at the Tehran University of Medical Sciences for funding this study. We also thank the manager and personnel of the medical records department of Imam Reza Hospital in Eslamshahr. This research was supported by Tehran University of Medical Sciences and provided with a health services grant (NO.30317). This article was extracted from the doctoral thesis of the first author.

\section{Conflict of Interests}

The authors declare that they have no competing interests.

\section{References}

1. Chisholm D, Evans DB. Improving health system efficiency as a means of moving towards universal coverage. World health report 2010.

2. De Maeseneer J, Willems S, De Sutter A, Van de Geuchte I, Billings M. Primary health care as a strategy for achieving equitable care. Health Systems Knowledge Network of the World Health Organization's Commission on Social Determinants of Health. 2007.

3. Atun R. What are the advantages and disadvantages of restructuring a health care system to be more focused on primary care services? [Internet]. Copenhagen: WHO Regional Office for Europe; 2004.

4. Van Lerberghe W. The world health report 2008: primary health care: now more than ever: World Health Organization; 2008.

5. World Health Organization. Regional consultation on strengthening the role of family/community physicians in primary health care. 2012.

6. Rashidian A, Joudaki H, Khodayari-Moez E, Omranikhoo H, Geraili $\mathrm{B}$, Arab M. The impact of rural health system reform on hospitalization rates in the Islamic Republic of Iran: an interrupted time series. Bull World Health Org. 2013;91(12):942-9.

7. Basu J, Mobley LR. Medicare managed care plan performance: a comparison across hospitalization types. Medicare Medicaid Res Rev. 2012;2(1).

8. Weissman JS, Gatsonis C, Epstein AM. Rates of avoidable hospitalization by insurance status in Massachusetts and Maryland. Jama. 1992;268(17):2388-94

9. Rosano A, Loha CA, Falvo R, Van Der Zee J, Ricciardi W, Guasticchi G, et al. The relationship between avoidable hospitalization and accessibility to primary care: a systematic review. Eur J Public Health. 2013;23(3):356-60.

10. Caminal J, Starfield B, Sánchez E, Casanova C, Morales M. The role of primary care in preventing ambulatory care sensitive conditions. Eur J Public Health. 2004;14(3):246-51.

11. Oleksiuk O. Avoidable hospitalization of children, morbidity and health care supply. Hygeia Public Health. 2013;48(2):234-7.

12. van Loenen T, van den Berg MJ, Westert GP, Faber MJ Organizational aspects of primary care related to avoidable hospitalization: a systematic review. Fam Prac. 2014; 31(5):502-516.

13. Shadpour K. Primary health care networks in the Islamic Republic of Iran 2000. Available from: http://www.who.int/iris/ handle/10665/118933.

14. Takian A, Rashidian A, Kabir MJ. Expediency and coincidence in re-engineering a health system: an interpretive approach to formation of family medicine in Iran. Health Policy Plan. 2010;26(2):163-73.

15. Takian A, Doshmangir L, Rashidian A. Implementing family physician programme in rural Iran: exploring the role of an existing primary health care network. Fam Prac. 2013; 30(5):551-559.

16. Alberta Health Services. Admissions for Ambulatory Care Sensitive Conditions: government of alberta. 2011. Available from: http://www.albertahealthservices.ca/Publications/ahs-pub-pr-def-ambcare-sensitive-cond.pdf

17. Purdy S, Griffin T, Salisbury C, Sharp D. Ambulatory care sensitive conditions: terminology and disease coding need to be more specific to aid policy makers and clinicians. Public Health. 2009;123(2):16973.

18. Freund T, Campbell SM, Geissler S, Kunz CU, Mahler C, PetersKlimm F, et al. Strategies for reducing potentially avoidable hospitalizations for ambulatory care-sensitive conditions. Ann Fam Med. 2013;11(4):363-70.

19. Friedman B, Basu J. Health insurance, primary care, and preventable hospitalization of children in a large state. Am J Manag Care. 2001;7(5):473-88

20. Saxena S, George J, Barber J, Fitzpatrick J, Majeed A. Association of population and practice factors with potentially avoidable admission rates for chronic diseases in London: cross sectional analysis. J R Soc Med. 2006;99(2):81-9.

21. Carvalho SC, Mota E, Dourado I, Aquino R, Teles C, Medina MG. 
Hospitalizations of children due to primary health care sensitive conditions in Pernambuco State, Northeast Brazil. Cad Saude Publica. 2015;31(4):744-54.

22. Krakauer H, Jacoby I, Millman M, Lukomnik JE. Physician impact on hospital admission and on mortality rates in the Medicare population. Health Serv Res. 1996;31(2):191.

23. Laditka JN, Laditka SB, Probst JC. More may be better: evidence of a negative relationship between physician supply and hospitalization for ambulatory care sensitive conditions. Health Serv Res. 2005;40(4):1148-66.

24. Ionescu-Ittu R, McCusker J, Ciampi A, Vadeboncoeur A-M, Roberge D, Larouche D, et al. Continuity of primary care and emergency department utilization among elderly people. CMAJ. 2007;177(11):1362-8

25. Menec VH, Sirski M, Attawar D, Katz A. Does continuity of care with a family physician reduce hospitalizations among older adults? J Health Serv Res Policy. 2006;11(4):196-201.

26. Long SH, Marquis MS. The uninsured'access gap'and the cost of universal coverage. Health Aff. 1994;13(2):211-20.

27. Wang S, Liu L, Li L, Liu J. Comparison of Chinese inpatients with different types of medical insurance before and after the 2009 healthcare reform. BMC Health Serv Res. 2014;14:443.

28. Guanais F, Macinko J. Primary care and avoidable hospitalizations: evidence from Brazil. J Ambul Care Manag. 2009;32(2):115-22. 